\title{
Comparison of bone mass and quality determinants in adolescents and young adults with juvenile systemic lupus erythematosus (JSLE) and juvenile idiopathic arthritis (JIA)
}

\author{
Fernanda Falcini ${ }^{1{ }^{*}}$, Loredana Cavalli ${ }^{2}$, Federico Bertini ${ }^{1}$, Marco Matucci Cerinic ${ }^{1}$, Maurizio De Martino ${ }^{3}$, \\ Maria Luisa Brandi², Stefano Stagi ${ }^{3}$
}

From 21st European Pediatric Rheumatology (PReS) Congress

Belgrade, Serbia. 17-21 September 2014

\section{Introduction}

Few prospective data have been published on the comparison of bone density and quality in homogeneous groups of patients with juvenile systemic lupus erythematosus (JSLE) and juvenile idiopathic arthritis (JIA).

\section{Objectives}

To perform a longitudinal evaluation of the prevalence and the characteristics of bone mass and quality in JSLE patients and to evaluate the differences on the bone biomechanical parameters, using DXA, pQCT, and QUS, in respect to two homogenous for age- and sex-groups of JIA patients and healthy controls.

\section{Methods}

Forty-three JSLE patients (35 females, 8 males, median age 18.8 years, range 14.0 - 34.1 years) have been crosssectionally studied with DXA, pQCT, and QUS scans and compared with 138 JIA patients (112 females, 26 males, median age 18.9 years, range 13.4 - 33.2 years: 89 oligoarticular, 26 poly, 8 systemic, 15 enthesitis-arthritis (ERA), and 79 healthy subjects ( 59 females, 20 males; median age 19.3 years, range 13.5 to 36.5 years). Of these, 39 patients (32 females and 7 males, median age 20.3 years, range 16.6 - 36.8 years) with JSLE were followed longitudinally and compared with 131 patients (108 females, 23 males median age 20.7, range 15.8 - 37.1 years) with JIA and 63 healthy subjects ( 48 females, 15 males; median age 21.9 years, range 15.5 to 38.3 years).

'Department of BioMedicine, Section of Rheumatology, Transition Clinic, University of Florence, Italy

Full list of author information is available at the end of the article

\section{Results}

JSLE patients have a higher bone cortical density (CrtBMD) than controls, with JIA patients $(\mathrm{p}<0.005)$, except the systemic subgroup ( $\mathrm{p}<0.0001)$, showing a lesser CrtBMD than controls and JSLE group. However, JSLE and JIA patients, except for ERA onset, have a significantly reduced bone trabecular density (TrbBMD) compared to controls $(\mathrm{p}<0.0001)$, with no differences between JSLE and JIA. In addition, JIA patients show a significantly reduced muscle area (muscle CSA) compared to JSLE and controls $(p<0.001)$. Conversely, fat area (fat CSA) is significantly increased in both JIA and JSLE patients when compared to controls $(p<0.001)$, with no differences between JSLE and JIA groups. Analogous results are observed in the polar resistance to stress (SSIp).

\section{Conclusion}

The evaluation of the main parameters that define bone density and structure in adolescents and young adults with JIA and JSLE highlights significant differences among the two groups and subgroups, and among JIA or JSLE patients and controls. These data might indicate a different pathogenesis of bone damage in the two entities, and suggest a different diagnostic and therapeutic approach to improve the peak bone mass.

\section{Disclosure of interest}

None declared. 


\section{Authors' details}

'Department of BioMedicine, Section of Rheumatology, Transition Clinic,

University of Florence, Italy. ${ }^{2}$ Department of Internal Medicine, Endocrinology

Unit, University of Florence, Italy. ${ }^{3}$ Health Sciences Department, Anna Meyer

Children's University Hospital, University of Florence, Florence, Italy.

Published: 17 September 2014

doi:10.1186/1546-0096-12-S1-P21

Cite this article as: Falcini et al:: Comparison of bone mass and quality

determinants in adolescents and young adults with juvenile systemic lupus

erythematosus (JSLE) and juvenile idiopathic arthritis (JIA). Pediatric

Rheumatology 2014 12(Suppl 1):P21.

Submit your next manuscript to BioMed Central and take full advantage of:

- Convenient online submission

- Thorough peer review

- No space constraints or color figure charges

- Immediate publication on acceptance

- Inclusion in PubMed, CAS, Scopus and Google Scholar

- Research which is freely available for redistribution

Submit your manuscript at www.biomedcentral.com/submit
Ciomed Central 